\title{
A ORQUESTRA E A VIDA Percursos juvenis na Orquestra Geração
}

\author{
João Teixeira Lopes \\ IS-UP, Porto, Portugal
}

Pedro dos Santos Boia

CIPEM, IPP, INET-md, Porto, Portugal

\author{
Ana Luísa Veloso \\ CIPEM, IPP, INET-md, Porto, Portugal
}

Matilde Caldas

Universidade Católica de Lisboa e CIPEM, Porto, Portugal

Resumo Na senda de uma sociologia da pluralidade disposicional, à qual se acrescenta a relevância do projeto e da construção de campos de possibilidade para a ação, analisam-se percursos juvenis de orquestra com base em retratos sociológicos, reconstituindo as transferências disposicionais entre os múltiplos processos e contextos de socialização, tendo por base a experiência na Orquestra Geração, projeto musical de inserção social com origem no El Sistema venezuelano. Assim, resgata-se a origem das disposições, bem como a força dos contextos da sua ativação (ou inibição), a par do seu potencial de transferibilidade para outros quadros de socialização. Conclui-se com o forte impacto da experiência orquestral na formação de novas competências e disposições, em desigual grau de intensidade consoante os atores, a singularidade dos seus percursos e os contextos em que se movem.

Palavras-chave: socialização, disposições, música, escola.

Abstract Following a sociology of dispositional plurality, to which is added the importance of the design and construction of possibility fields for action, we analyse youth orchestra pathways based on sociological portraits, reconstituting dispositional transfers between contexts and processes of socialization, based on the Generation Orchestra experience, which is a musical project of social inclusion originating in Venezuelan El Sistema. In this way, we intend to rescue the origin of dispositions and the strength of the contexts of their activation (or inhibition), together with its potential transferability to other frameworks for socialization. We conclude with the strong impact of orchestral experience in the formation of new skills and dispositions in uneven degree of intensity depending on the actors, the uniqueness of its pathways and the contexts in which they move.

Keywords: socialization, dispositions, music, school.

Résumé Dans le sillage d'une sociologie de la pluralité dispositionnelle, à laquelle on ajoute l'importance du projet et de la construction de champs de possibilité d'action, sont analysés les cours des jeunes de l'orchestre sur la base de portraits sociologiques, en reconstituant les transferts entre les multiples contextes et les processus de socialisation, basé sur l'expérience de l'Orchestre Génération , projet musical d'inclusion sociale originaire de El Sistema vénézuélien. Ainsi, on cherche l'origine des dispositions et de la force des contextes de leur activation (ou de leur inhibition), avec son potentiel de transférabilité à d'autres cadres de socialisation. On conclut avec le fort impact de l'expérience orchestrale dans la formation de nouvelles compétences et dispositions en degré d'intensité inégale selon les acteurs, le caractère unique de ses itinéraires et les contextes dans lesquels ils se déplacent.

Mots-clés: socialisation, dispositions, musique, école. 
Resumen En el sendero de una sociología de la pluralidad disposicional, al cual se añade la relevancia del proyecto y de la construcción de campos de posibilidad para la acción, se analizan trayectos juveniles de orquesta con base en retratos sociológicos, reconstituyendo las transferencias disposicionales entre los múltiples procesos y contextos de socialización, teniendo por base la experiencia en la "Orquestra Geração", proyecto musical de inserción social con origen en El Sistema Venezolano. Así, se rescata el origen de las disposiciones, así como la vitalidad de los entornos de activación (o inhibición) y su potencial de transferencia para otros entornos de socialización. Se concluye con el fuerte impacto de la experiencia orquestal en la formación de nuevas competencias y disposiciones, en grado de intensidad diferenciado según los actores, la singularidad de sus recorridos y los contextos en que se mueven.

Palabras-clave: socialización, disposiciones, música, escuela.

\section{Notas introdutórias: uma pesquisa sobre socialização}

A Orquestra Geração (OG) foi criada em Portugal em 2007, inspirando-se no El Sistema e, à semelhança do projeto venezuelano, focando-se numa perspetiva de inclusão social através da música e dirigindo-se prioritariamente a crianças e adolescentes em situação de maior risco e vulnerabilidade educativos e sociais. O primeiro núcleo da Orquestra Geração surge em outubro de 2007 apoiado pelo programa comunitário EQUAL, integrando alunos da Escola Miguel Torga, na Amadora. Em 2008-2009 desponta um outro núcleo do projeto, o do Casal da Mira, e no período de 2009-2010 a 2011-2012 expande-se para mais cinco escolas da área metropolitana de Lisboa e uma no norte do país, em Mirandela. As respetivas populações têm, à semelhança do núcleo inicial da Amadora, tendencialmente as mesmas características sociais, marcadas por contextos de forte relegação territorial. Como comunidades de prática musical (Wenger, 2006) em contextos não formais, estamos perante um paradigma de intervenção cujas vertentes podem e devem ser investigadas sistematicamente. Até ao momento, para além do trabalho de Sanchez (2008), não são conhecidas investigações extensivas que abordem o contexto do El Sistema na Venezuela. Em Portugal, Caldas (2007) elaborou uma tese de licenciatura em Antropologia na qual, a partir da descrição do projeto venezuelano e do início da implementação do projeto Orquestra Geração na Amadora, procura o contributo de uma antropologia aplicada face a políticas de intervenção social. Bento, por seu lado, explora etnograficamente o conceito de "campo de estratégias criativas", partindo da rede de interações da orquestra em cruzamento com os contextos de desigualdade social de bairro (Bento, 2014).

Este artigo $^{1}$ procurará demonstrar, através da análise de 35 retratos sociológicos, as competências e disposições criadas, mobilizadas ou inibidas durante a experiência orquestral, tentando sempre descortinar o efeito de percurso ao longo do processo de socialização, bem como o potencial de transferibilidade dessas competências e

1 Os autores agradecem os contributos críticos de Graça Mota, Matilde Caldas e Benedita Portugal e Melo. 
disposições para outros mundos da vida. ${ }^{2}$ Considerando as inter-relações entre família, escola, bairro, redes de sociabilidade e a socialização orquestral, procuraremos, então, compreender como esta última pode ser consequente sobre as disposições dos participantes, alterando-as em graus desiguais, assim como a maneira através da qual os percursos anteriores e exteriores à OG condicionam e filtram o próprio processo de incorporação de novas disposições (Boia e Lopes, 2012).

\section{Em busca da pluralidade disposicional}

Os retratos sociológicos permitem-nos "puxar" pelos diferentes fios que produzem socialmente os sujeitos, através das socializações múltiplas à escala individual. $\mathrm{Na}$ senda de Bernard Lahire (1998, 2002, 2012), procuraremos desvendar quer a génese das disposições incorporadas pelos estudantes da Orquestra Geração (OG), quer as plurais formas do seu cruzamento e articulação ao longo do percurso de vida individual, num jogo de ocultação e desvendamento que constrói as biografias dos atores sociais sem os conceber como réplicas pós-modernas de uma sociedade estilhaçada, isto é, amnésica face a princípios ou propriedades de estruturação. Tanto a coerência (queé possível existir em percursos lineares onde os mesmos princípios de socialização são constantemente ativados pelas situações, numa espécie de sobreaprendizagem) como a heterogeneidade (fruto da disparidade de orientações das multissocializações e da multiplicação de contextos, quadros de interação e papéis sociais) são "casos do possível", com graus, nuances e interseções finas e variadas, combinando-se em cada indivíduo através da constituição de singularidades ou "coeficientes de singularidade", eles mesmos resultado do cruzamento (único e irrepetível, embora enquadrável em tendências e, por vezes, em regularidades) de dimensões estruturais, institucionais, interacionais e biográficas (Costa, Lopes e Caetano, 2014).

Uma disposição (forma coerente, durável e sistemática de pensar, agir e sentir) tem uma determinada origem e trajetória, na qual ganha ou perde força, consoante é ou não ativada e mobilizada pelos contextos (Lahire, 1998). Não podemos simplesmente "supô-la" como entidade omnipresente e omnipotente que ajusta automaticamente os indivíduos às situações (ou o presente ao passado). Muitas delas não são verdadeiramente disposições, uma vez que existem como recursos, capacidades ou competências. Para analisá-las, importa levar a sério a ideia de que a sociologia é, antes de mais, o estudo dos processos de socialização, necessariamente múltiplos em sociedades diferenciadas, complexas e compostas por esferas de

2 Este trabalho é financiado pelo Fundo Europeu de Desenvolvimento Regional (Feder), através do Programa Operacional Fatores de Competitividade (Compete), e por fundos nacionais, através da Fundação para a Ciência e a Tecnologia (FCT), no âmbito do projeto PTDC/CPE-CED/120596/2010. $\mathrm{O}$ artigo resulta da pesquisa subjacente ao projeto "Promover a Inclusão Social através do Envolvimento com a Música - O Projeto Orquestra Geração", coordenado por Graça Mota e abrangendo uma vasta equipa pertencente ao CIPEM (Centro de Investigação em Psicologia da Música e Educação Musical), polo do IPP do INET-md (Instituto de Etnomusicologia - Centro de Estudos em Música e Dança) e ao Instituto de Sociologia da Universidade do Porto. O trabalho de campo desenrolou-se entre 2013 e 2015. 
atividade ou "mundos da vida" razoavelmente específicos e institucionalizados, assentes em conjuntos de agentes, valores e "domínios de práticas" (família, trabalho, lazer, sociabilidades, corpo...), amiúde decompostos em microcontextos, situações ou cenários de interação (Lahire, 1998 e 2012). Assim, existe uma multideterminação do grau de homogeneidade ou heterogeneidade do stock ou "património de disposições incorporadas pelos atores" no decurso das socializações.

Como veremos pelos 35 retratos de jovens da OG, nem todas as disposições adquiridas na e pela orquestra resultam dos quadros familiares, eles próprios segmentados e perpassados por influências exodomiciliares. Por outro lado, algumas delas funcionam com a escola; outras contra ela. Outras, ainda, opõem-se com maior ou menor força às matrizes socializadoras do "bairro", também ele internamente diferenciado. Na articulação e na combinação múltipla e fecunda que no percurso do indivíduo se vão gerando, abrem o espaço para que "cada ponto da trajetória possa ser o momento de uma crise, de uma negociação, de uma dúvida, de uma hesitação entre várias possibilidades, de uma resistência ou de um constrangimento" (Lahire, 2002: 30) forjados nas relações e quadros ou configurações de interdependência entre os indivíduos. Existem, pois, disposições mais contextualizadas e situadas do que outras, uma vez que nos reenviam ou para um certo contexto (o "bairro", a "família", "a escola", a "orquestra"), ou para uma particular fase de vida do indivíduo (a transição para a adolescência, a autonomização face à família ou ao grupo de amigos), variando, pois, no seu grau de transferibilidade que, insistimos, não pode ser meramente pressuposto, antes verificado pela repetição, recorrência, mobilização de "traços disposicionais" (atitudes, propensões, tendências comportamentais, linguagens e expressões persistentes...) numa certa duração e em cada caso concreto.

Em suma, disposicionalismo e contextualismo exigem-se mutuamente. As disposições são ativadas, inibidas e/ou transformadas pelos contextos. Elas existem sempre sob essa condição. Daí que Lahire, atualizando Bourdieu (que propunha: [(habitus) (capital)] + campo= prática), sugira as seguintes fórmulas analíticas, nas quais nos baseamos para a elaboração do guião dos retratos sociológicos:

- $\quad$ disposições ou competências + contexto = práticas (reenvia para o passado das socializações que permitiram a incorporação de disposições ou competências, mas cruza-o com os contextos de ação presentes, convocando quer a exigência de não esquecer o passado, quer a premência de ter em conta o contexto);

- passado incorporado + contexto presente = práticas observáveis (realçando, agora, o facto de que as disposições nunca se observam diretamente, uma vez que remetem para o seu processo e modo de produção enquanto " presença passada - mais ou menos precoce, durável, sistemática - em diversos contextos de ação" (Lahire, 2012: 26);

- produtos interiorizados pela frequência passada de contextos de ação + contexto presente $=$ práticas observáveis (o que realça a dupla perspetiva dos contextos presentes, quer enquanto configuração que desencadeia (ou inibe) disposições incorporadas, quer enquanto quadro socializador que atualiza, transforma e produz novas experiências, modificando disposições passadas, de um modo mais ou menos intenso, no limite gerando mesmo novas disposições). 
Pela nossa parte, gostaríamos ainda de acrescentar uma dimensão de intencionalidade, reflexividade e antecipação do futuro (dentro das expetativas moldadas pela perceção dos possíveis e das margens da sua ampliação). Os atores sociais, dentro de um feixe de constrangimentos e possibilidades, que configuram modos desiguais de agência (ou desigualdades de agência, que se articulam, sem necessariamente se sobreporem, a desigualdades estruturais - de classe, género, etnia...), conseguem, melhor ou pior, negociar os significados das situações, mesmo as futuras, de acordo com o seu projeto e o seu potencial de metamorfose, conceitos que pedimos emprestados a Gilberto Velho (2003). Por projeto, o antropólogo urbano brasileiro entende a capacidade de prosseguir determinados objetivos, de forma consciente ou tácita, organizada ou errante, com tradução em modalidades múltiplas e por vezes performativas de interpretação e definição da realidade. Ora, de acordo com os recursos e competências de trânsito entre realidades, contextos e papéis sociais distintos (potencial de metamorfose), o ator social poderá imaginar futuros possíveis, dado que essa representação, longe de ser um quadro desligado da realidade objetiva, terá consequências no presente, o que quer dizer na própria adaptação, atualização e transformação do passado incorporado.

Assim, para melhor captarmos a génese das disposições dos jovens da Orquestra Geração, propomos a seguinte proposição analítica:

Passado incorporado $\leftrightarrow$ contextos presentes de ação $\leftrightarrow$ projeto e imaginação de futuros possíveis $=$ práticas observáveis

De alguma forma, é no aqui e agora da pesquisa de terreno (o presente etnográfico) que estas várias dimensões da ação podem ser reconstituídas através de estratégias de observação, como os retratos sociológicos (Lopes, 2014).

Como realça Cristina Roldão (2014), Lahire procura alargar e sistematizar o potencial de abertura teórica que Bourdieu concede ao falar no habitus como "produto da história", noção implícita quando o autor de $A$ Distinção analisa casos de habitus clivados (trajetórias em que um ator é socializado em quadros fortemente contrastantes, em termos de classe ou de etnia) ou de hysteresis do habitus (o famoso "efeito D. Quixote", que exprime o hiato entre uma socialização passada e novas condições de existência profundamente distintas, o que ocorre em percursos de franca mobilidade social). Lahire, como o referimos, recusa, particularmente, o cariz unificador de todas as práticas em todas as situações. Ao fazê-lo, o sociólogo de O Homem Plural não resvala para uma qualquer desordem rizomática, mas aproxima-se do conceito de configuração de Norbert Elias (1994), enquanto rede de interdependências cruzadas entre os indivíduos: “Essa multiplicidade de disposições [lembra Roldão] não estaria simplesmente armazenada como um 'amontoado', mas organizada segundo diferentes princípios de indexação [no caso em análise, a orquestra, a família, a escola, o bairro, as redes de amigos] relativos aos contextos de socialização, em repertórios de esquemas de ação que, embora distintos (porque reportam a contextos de socialização diferentes), teriam conexões entre si" (id. ibid.: 77-78).

Não nos parece, pois, que necessitemos de uma substituição do conceito de habitus pelo de património individual de disposições, embora tal superação, proposta por 
Lahire, pretenda distinguir entre os casos (possíveis) de unificação e transferência de maneiras de agir, pensar e sentir (os habitus) dos percursos (também possíveis e diríamos mesmo mais frequentes) em que a pluralidade se impõe. De igual modo, as condições de existência consubstanciais à formação do habitus são elas próprias multidimensionais (Setton, 2010) e não redutíveis às variáveis de classe (origem e trajetória), alargando-se à constelação ou rede de papéis sociais. Mas, por que não falar em habitus plurais, dotados de incongruências, plasticidade e metamorfose, mantendo o amplo uso do conceito (embora muitas vezes mecanizado e até neutralizado) e permitindo uma maior cumulatividade das pesquisas sobre a génese e a transferência das disposições?

Por outro lado, necessitamos de incluir as dimensões da reflexividade no centro da análise (Melo, 2005). Mesmo sabendo que nem sempre os atores são agentes e que essa transmutação mobiliza diferentemente recursos desiguais, mesmo cientes de que reflexividade e criatividade ou inovação não são necessariamente concomitantes (uma vez que o exercício da reflexividade, em contextos sociais determinados, pode resultar na reprodução dos sistemas, por exemplo quando os agentes se consciencializam da impossibilidade da mudança), existem neles disposições que superam as práticas pré-reflexivas e que elaboram as estruturas, no sentido que Archer (2003) lhes atribui, enquanto feixes de constrangimento mas também de capacitação, em constante atualização e concretização pela ação social. Como refere Caetano (2011):

O que resulta do exercício da reflexividade depende sempre da articulação entre fatores estruturais, contextuais e pessoais. Para compreender a relação entre reflexividade e agência é, por isso, necessário ter em conta quais as condições sociais de possibilidade que permitem que as deliberações reflexivas se transformem em ação criativa (id. ibid.: 161).

Parece-nos que importa analisar, seguindo Lahire, os processos através dos quais os patrimónios individuais de disposições podem ser questionados e tomados como objetos pelos atores, em desiguais graus de envolvimento contextual, e mesmo os momentos mais ou menos organizados de rutura com os mecanismos implícitos e não conscientes da ação e que superam a mera incorporação dos princípios e processos múltiplos de socialização. Ora, os retratos sociológicos pretendem aguçar, precisamente, esse tipo particular de reflexividade, que aqui chamaremos reflexividade sociológica dos agentes enquanto sujeitos (e que não esgota, como relembra Caetano, o pensamento e a ação reflexivos), criando uma ocasião (a pesquisa, o momento etnográfico, o circuito hermenêutico da entrevista - cf. Bourdieu, no seu texto "Comprendre", 1993) de expressão do seu pensamento sobre os seus posicionamentos societais, o desempenho e a interpretação dos papéis sociais, os contextos que o cerceiam e capacitam, a sua (in)existente margem de manobra, os seus modos de relação com os mundos do mundo.

Em suma, retomando o exercício, a respeito de Bourdieu, que DeNora (2003) praticou a partir do legado de Adorno, não temos de nos resumir à maniqueísta dicotomia entre acólitos e oponentes. Na verdade, devemos aproveitar as heranças 
teóricas que tão fortemente influenciaram pesquisas afins (caso da teoria da prática de Bourdieu) para pensarmos em termos dialógicos, em rede, em tensão, perscrutando todo o terreno existente entre o ponto e o contraponto, incluindo o balanço das críticas que visam a atualização dessa herança, de maneira a fazermos pesquisa não apenas com e contra mas sobretudo a partir de (Corcuff, 2002) e por vezes além de, desenvolvendo uma sociologia eclética que, escutando a realidade, não se reduza à mera reprodução acrítica de uma ou outra tradição teórica (Boia, 2015).

\section{Metodologia e panorâmica dos retratos}

Os retratos sociológicos foram construídos com base em entrevistas semidiretivas, aplicadas por diferentes membros da equipa de investigação a estudantes de escolas e de associações onde a OG está inserida. Sempre que possível, realizaram-se duas sessões com os entrevistados. Preferencialmente, quem realizou as entrevistas elaborou o retrato. Quando tal não aconteceu, trocaram-se sistematicamente informações entre os diferentes elementos da equipa, sendo os retratos validados por pelo menos três investigadores e constituindo, por isso, um produto coletivo.

O guião comportava seis grandes contextos de socialização: escola; família e parentesco mais alargado; eventual inserção no mercado de trabalho; o território de residência, entendido aqui numa escala que vai da casa aos quadros de sociabilidade local; os amigos e as esferas afetivas; e, finalmente, a orquestra. Tal como anteriormente referimos, procurámos não só situar contextualmente as disposições e orientações para a ação, como também as transferências e interdependências que entre elas se estabelecem ao nível de cada percurso. O fio diacrónico (diferentes momentos do ciclo de vida) está bem presente, de maneira a salientar o efeito de percurso das próprias variações intraindividuais, no confronto/alternância entre disposições contraditórias ou até contrastantes e da evolução dos modos de relação com os constrangimentos contextuais (quais os momentos de maior ou menor mobilização de recursos; quais as fases de maior ou menor ativação das experiências passadas; qual o peso das novas situações presentes, nomeadamente através da orquestra, etc.).

Para além disso, o guião pretendia recolher informação sobre os capitais de origem do agregado familiar e a inserção escolar dos jovens, terminando com uma ativação das competências reflexivas, ao convocar sugestões de reorientação, quer quanto à orquestra, quer quanto às restantes esferas de vida, procurando, uma vez mais, a sua conexão.

Optámos, ainda, na versão integral, por dar um título a cada retrato, algo que desagradaria a Lahire, uma vez que o autor defende a resistência à tentação de fazer ressaltar uma lógica dominante ou "forçar o traço", "condensando a singularidade destas pessoas numa fórmula relativamente simples", uma vez que "as diversas práticas, atitudes... de um indivíduo não são redutíveis a uma forma generalizadora" (Lahire, 2002: 43). No entanto, temos a convicção de que o título poderá exprimir o coeficiente de singularidade de cada retrato, permitindo ao leitor um fio de Ariadne para a leitura integral e uma sugestão de confronto com regularidades ou padrões e não o forçar de uma coerência artificial. 
No que se refere à seleção dos entrevistados, seguimos alguns critérios simples:

- dar preferência, sempre que possível (isto é, existindo disponibilidade por parte dos entrevistados) a jovens com um percurso mais longo na orquestra, $\mathrm{o}$ que permite uma mais intensa acumulação de experiências;

- procurar diversidade etária e de circuito escolar (ensino genérico/ensino especializado de música; distintos estabelecimentos escolares: Escola EB 2/3 de Vialonga; Escola EB 2+3 Miguel Torga; Escola Básica 1+2 da Apelação; várias escolas básicas de Amarante associadas ao Centro Cultural de Amarante);

- encontrar alguma diversidade de género (não conseguida, dada, por um lado, a sobrerrepresentação feminina na orquestra e, por outro, a muito maior disponibilidade das raparigas para falarem do seu percurso - 14 casos contra apenas três masculinos);

- estudar, ainda, contextos territoriais distintos (área metropolitana de Lisboa/Amarante).

Os nomes são fictícios, de acordo com as indicações dos próprios entrevistados.

\section{Origens sociais}

As idades dos 35 retratados variam entre os 13 e os 19 anos e a escolaridade entre a frequência atual do ensino básico (23 casos), do ensino secundário (dez casos) e do ensino superior politécnico (dois casos).

Do ponto de vista das origens sociais, estes entrevistados pertencem, na sua esmagadora maioria, ao universo heterogéneo das classes populares ou "classes assalariadas de base" (Costa, 2012: 115). Independentemente da fração de classe, estamos na presença de famílias com parcos recursos em propriedade, subalternas em termos de posição formal nas organizações (trabalhos manuais da indústria, construção e transportes ou assalariados de rotina e execução do terciário, sem controle sobre os ritmos e processos de trabalho e sem o exercício de funções de supervisão) e em qualificações e recursos escolares, embora neste domínio a situação seja mais diversa. As exceções são escassas, como se constata pelo quadro 1:

Do ponto de vista das estruturas familiares, verifica-se uma certa diversidade. Apesar de predominarem (16 casos) as famílias nucleares (casal e filhos, incluindo estruturas recompostas), existem situações de famílias monoparentais (oito casos) e de famílias alargadas (nove casos), com presença de avós ou tios e marcadas pela partilha de rendimentos e entreajuda.

Encontramos, igualmente, retratados com origens étnico-nacionais distintas (particularmente com raízes africanas, mas também dois casos de famílias provenientes da Europa de Leste), o que nos remete para a possível interseção entre desigualdades sociais de classe e de etnia. Por outro lado, dos 70 progenitores, dez estão em situação de desemprego. Finalmente, importa destacar várias menções a situações de precariedade, intermitência laboral, estágios de formação profissional ou mesmo de economia informal. 
Quadro 1 Lugares familiares de classe

\begin{tabular}{lr}
\hline Operários industriais & 10 \\
Empregados executantes & 10 \\
Trabalhadores independentes & 3 \\
Profissionais técnicos e de enquadramento & 4 \\
Sem informação suficiente & 8 \\
Total & 35 \\
\hline
\end{tabular}

No entanto, apesar de notórias dificuldades económicas, não notamos nestas famílias situações de exclusão extrema. Persistem redes de solidariedade e apoio (parentesco, particularmente, uma vez que o próprio agregado familiar abarca amiúde avós, tios, etc.), a par de contextos habitacionais relativamente favoráveis (os jovens referem, em geral, viverem em apartamentos amplos e com um quarto para si), muitos deles inseridos em bairros de habitação social onde a presença, ainda que errática, do estado-providência, se faz sentir. Para perceber a amplitude das desigualdades e carências sociais devemos, a todo o momento, perceber a importância quer dos processos económicos, particularmente os que se referem às posições no mercado de trabalho, quer dos restantes quadros de socialização (redes sociais, território, instituições, etc.), alguns deles perpassados pelas lógicas e contradições das políticas públicas em contexto de crise.

\section{Socializações: contextos, disposições e percursos}

Os quadros que em seguida apresentamos sublinham uma análise exploratória horizontal dos entrevistados que, sem dispensar noutras instâncias um aprofundamento vertical das singularidades, permite a comparação de dimensões do processo de socialização, como a influência de figuras marcantes, a importância de contextos distintos, a socialização por antecipação (em referência aos projetos de futuro) ou ainda os modos particulares de relação com os universos musicais e a inserção na OG.

De igual modo, pretendemos compreender os contextos e fatores sociais que favorecem a eficácia de um programa forte de socialização por parte da orquestra. Por este conceito, entendemos a ativação e/ou criação, em contexto de orquestra, de disposições, orientações de ação e/ou competências, aí originadas ou fortalecidas, no caso de provirem de outras instâncias de socialização, e dotadas de potencial de transferibilidade e metamorfose para distintos quadros de socialização. Assim, torna-se relevante perceber quais as disposições preexistentes (interiorizadas no seio familiar, por exemplo) que são bloqueadas ou até eliminadas pela exposição aos princípios socializadores da OG, bem como as que são criadas a partir da experiência orquestral e transferidas para outras esferas.

A análise horizontal prolonga-se tentando descortinar os feixes de consonância/dissonância entre princípios socializadores dos vários contextos que atravessam o percurso dos atores, tomando por base de comparação a experiência na OG. 
Quadro 2 Figuras de referência (resposta múltipla) dos estudantes da OG

\begin{tabular}{|c|c|c|c|c|c|}
\hline Mãe & Pai & $\begin{array}{c}\text { Ambos os } \\
\text { progenitores }\end{array}$ & $\begin{array}{l}\text { Tios/avós/irmãos } \\
\text { /padrinhos }\end{array}$ & $\begin{array}{c}\text { Professores } \\
\text { e maestros da OG }\end{array}$ & Não refere \\
\hline 9 & 3 & 6 & 10 & 6 & 9 \\
\hline
\end{tabular}

Quadro 3 Génese e transferência de disposições e competências

\begin{tabular}{lll}
\hline Cria & Favorece/ativa & Inibe \\
\hline - Competências favoráveis ao & - Disposições familiares de & - Disposições de fuga, abandono \\
sucesso escolar: disciplina e & incentivo direto e/ou implícito à & e anomia (Rodrigo, Jorge, Pedro, \\
organização dos espaços-tempo, & aprendizagem (Natasha, Ana, & Raquel). \\
coordenação, entreajuda, ethos de & Camila, Isabel, Lúcia, Tânia, & - Redes de sociabilidade \\
aprendizagem coletiva (Natasha, & Cátia, Lucinda, Rosa, Luísa, & preexistentes (Rodrigo, Jorge, \\
Ana, Rosa, Pedro, Marta, Lúcia, & Joana, Dafne, Djamila, Joaquim, & Pedro, Manuela). \\
Tânia, Cátia, Lucinda, Yami, & Vanessa, Tanishia). & \\
Dafne, Djamila, José, Leiza, & - Disposições musicais anteriores & \\
Ricardo, Vanessa, Tanishia, Alice, & (Natasha, Camila, Lúcia, Joana, & \\
Sofia, Gustavo, Leonor, Manuela). & Dafne, Leiza, Vanessa). & \\
- Disposições musicais afetivas & - Propensão à mobilidade social & \\
(amor/paixão pela música e/ou & (Ana, Rosa, Isabel, Joana, Pedro, & \\
instrumento) (Natasha, Jorge, & Ricardo). & \\
Marta, Lúcia, Luísa, Joana, Dafne, & - Orientação profissional para o & \\
Jamélia, Joaquim, Leiza, Niara, & mundo da música (Jorge, Isabel, & \\
Ricardo, Vanessa, Tiago). & Marta, Lúcia, Yami, Luísa, Pedro, & \\
- Disposições musicais reflexivas & Joana, Natasha, Vanessa, & \\
(Marta, Joana, Jamélia, Vanessa, & Gustavo). & \\
Tiago). & & \\
- Disposições relacionais, de & & \\
abertura aos outros/integração no & & \\
grupo e sentimento de pertença & & \\
(Rosa, Marta, Yami, Dafne, Daniel, & & \\
Djamila, Jamélia, Joaquim, José, & & \\
Leiza, Vanessa, Alice, Sofia, & & \\
Leonor, Manuela). & & \\
\hline
\end{tabular}

A primeira constatação (quadro 2) realça a pluralidade de figuras de referência para os entrevistados. O núcleo familiar primordial aparece frequentemente referido (pais e irmãos), o que parece associar-se, na maior parte dos casos, a uma relação favorável com a família de origem. Mas há também alusões ao parentesco mais alargado (avós e tios) e mesmo a pessoas do universo da OG (professores de música e maestros). Contudo, nove casos não mencionam influências marcantes, $\mathrm{o}$ que poderá indiciar uma condição de anomia ou fraqueza relacional.

A segunda constatação leva-nos a realçar que a experiência da OG produz algum tipo de efeito disposicional em todos os retratados, com exceção de Raquel, porventura o caso mais exposto a possibilidades de exclusão social. Esta retratada desenvolve uma reflexividade de protesto, de resistência à aprendizagem em 


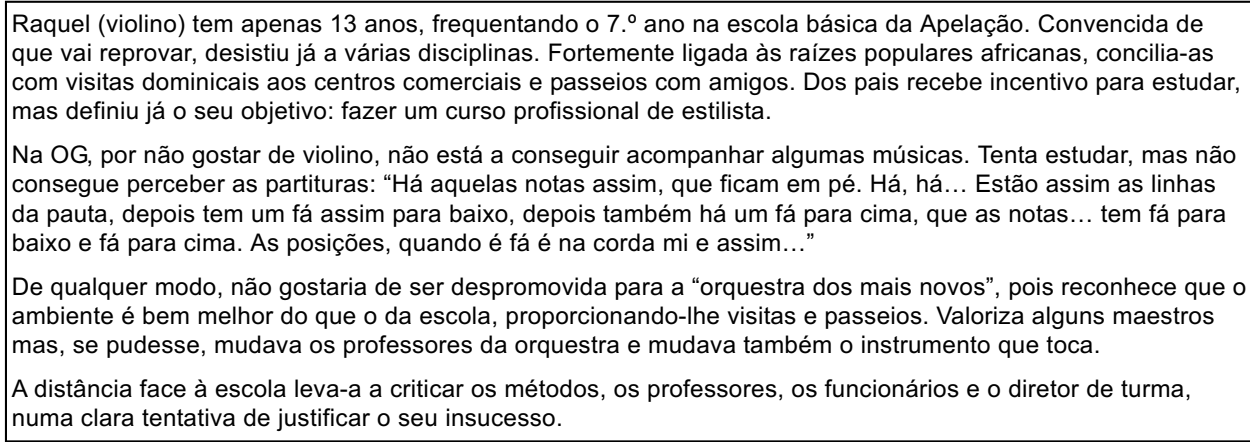

múltiplos contextos (Willis, 1977), sem procura aparente de caminhos alternativos, o que se deve, em parte, aos escassos recursos que possui (o potencial de reflexividade construtiva e de definição identitária é bastante permeável à desigualdade de recursos - cf. Caetano, 2011; Vieira, 2007), já que as privações de capital económico e cultural se intersetam, porventura, com a origem étnica, ainda que não se refira explicitamente a situações de discriminação.

No entanto, terceira constatação, a amplitude dos efeitos desta socialização orquestral sobre os participantes é variável consoante os retratos: em alguns, perpassa quase todas as dimensões consideradas. Noutros, é mais tangencial. Na nossa amostra constata-se que eles parecem mais permeáveis à socialização de bairro e às sociabilidades locais, tantas vezes dissonantes face ao projeto escolar. Processos de socialização de género favorecem nas raparigas disposições mais intensas de adesão à ordem escolar, dado o maior domínio de competências relacionais e de antecipação de expetativas, ao contrário dos rapazes, que incorporam orientações hedonistas e agonísticas, pautadas por lógicas de resistência aos modos e ritmos de aprendizagem - cf. Lopes, 1997), sendo esta diferença tanto maior quanto mais desfavorecido se afigura o meio social de pertença (Baudelot e Establet, 1992).

Quarta constatação: a situação mais referida prende-se com a criação de competências favoráveis ao sucesso escolar (autodisciplina e organização dos espaços-tempo, coordenação, entreajuda, ethos de aprendizagem coletiva). Reside aqui, afinal, a força simbólica e prática da orquestra: a transmissão de um saber-fazer e saber-estar em conjunto, "afinado", em que as improvisações individuais só são permitidas dentro de uma coexistência normativa comum, numa equilibrada composição de cooperação e competição, o que nos remete quer para a importância da empatia e intersubjetividade performativa, o chamado tuning mútuo/sincronização sócio-musical entre os músicos (Schütz, 1951) implicados na prática de 'musicar'/musicking (Small, 1998) em conjunto. Ora, esta incorporação favorece a transferência de tais disposições e competências para contextos escolares, assim como a própria construção do "ofício de aluno" (Perrenoud, 1994), bem como um diapasão de organização das redes e situações de sociabilidade. 
(In)sucesso escolar dos estudantes que integram a OG

\begin{tabular}{ccc}
\hline Sucesso escolar elevado & Sucesso escolar & Insucesso escolar \\
\hline 7 & 25 & 3 \\
\hline
\end{tabular}

No entanto, quinta constatação, parece também claro que esta criação é, em parte, um reforço de disposições anteriormente criadas no universo doméstico. Vários estudos têm acentuado que, mesmo as mutáveis e plurais configurações familiares contemporâneas continuam a exercer um forte trabalho educativo, com transmissão intensa de patrimónios normativos e matrizes culturais (recriadas constantemente pelos indivíduos - cf. Pappámikail, 2013). Estamos em presença, na verdade, de jovens oriundos de famílias de classes populares que, apesar de dificuldades, nalguns casos vincadas (desemprego e subemprego), não deixam de investir ou em recursos educativos, ou em formas mais ou menos difusas de incentivo e suporte, favoráveis a uma "ordem moral doméstica" (Lahire, 1995) regrada, o que permite forças de consonância e interdependência entre família, escola e OG, bem como a manutenção de condições de transmissão dos (fracos) recursos escolares e educativos familiares. Estas formas de mobilização familiar contribuem quer para o evitamento de situações objetivas e subjetivas de exclusão e desclassificação social, quer mesmo para percursos marcados pela propensão à distinção face aos contextos de pertença (bairro, grupos de pares) estigmatizados, favorecendo a emergência ou a consolidação de projetos de mobilidade social. Também aí a OG parece desempenhar um papel importante, fornecendo repertórios e recursos para a imaginação de futuros possíveis que não passem pela fatalidade ou pela sentença da profecia dos trabalhos manuais e subalternos (casos de Ana, Rosa, Isabel, Joana e Pedro, por exemplo).

Sexta constatação: onde a experiência OG parece disseminar-se de um modo menos forte é no domínio das práticas culturais e de lazer. ${ }^{3}$ Mesmo nos casos que se orientam para um futuro profissional nos mundos da música, os gostos continuam geralmente marcados pelo universo pop, por vezes recheado dos ícones do momento; da comunicação mediada por computador, com ampla utilização das redes sociais (apesar de um ou outro caso de resistência ao facebook e à pop da moda); das práticas doméstico-recetivas associadas à televisão; da convivialidade de base local (amigos, família) ou com alguns passeios ao centro comercial. Raros são os participantes que referem a procura de repertórios eruditos, o culto de referências clássicas ou a prática auditiva sistemática. Mesmo quando o fazem, surge com nitidez um contorno instrumental (por exemplo, procurar alguma visualização no YouTube com o intuito de aprimorar a performance das peças que estão a estudar).

3 Há uma dissonância ou dissonância relativa entre as práticas de lazer extra-OG e o tipo de cultura e repertório representados pela OG em 26 casos $(74,28 \%)$ e uma consonância ou consonância relativa em sete casos (20\%). Dois casos são difíceis de categorizar, podendo ser vistos quer como consonância, quer como dissonância relativa. 
Pedro (trompete) tem 16 anos, frequenta a Escola Profissional Metropolitana de Lisboa e vive com os pais na Brandoa, com fortes dificuldades, de tal modo que dois irmãos emigraram para Inglaterra. Reconhece na OG um contexto de criação de novas disposições, que lhe permitiram reinventar-se identitariamente, cortando com um percurso de retraimento, imaturidade e marcado por um episódio de insucesso escolar. Agora, é capaz de se autonomizar e estabelecer distâncias e fronteiras (próprias do processo de identização - Tap, 1986), uma vez mais face a certas zonas do "bairro" (ao qual afirma não pertencer, já que a sua habitação não está na área de realojamento social), mas também em relação aos jovens da escola ("essas criancinhas que andam por aí e que gostam de armar confusão"). De alguma forma, a orquestra deu-lhe um rumo ("aqui ao menos faço alguma coisa, estou mais ativo, gasto mais energias") e um sentido que não encontrava na escola ("nas aulas estou sempre calado e fico com sono e pronto!"). Além do mais, ao incutir-lhe um novo projeto de futuro, que agora imagina no mundo da música, a orquestra representa, em termos práticos e simbólicos, uma fuga à fatalidade anunciada da trilogia da "rua", da droga e do insucesso escolar.

Figura 2 Excerto de retrato: Pedro e a eventual superação da fatalidade

Quadro 5 Consonâncias e dissonâncias entre contextos de socialização

\begin{tabular}{|c|c|c|c|c|}
\hline $\begin{array}{l}\text { Dissonância } \\
\text { escola/OG }\end{array}$ & $\begin{array}{l}\text { Dissonância } \\
\text { família/OG }\end{array}$ & $\begin{array}{l}\text { Dissonância entre } \\
\text { redes } \\
\text { de sociabilidade }\end{array}$ & $\begin{array}{l}\text { Dissonância entre } \\
\text { repertório OG } \\
\text { e práticas culturais }\end{array}$ & $\begin{array}{l}\text { Dissonância } \\
\text { "bairro"/OG }\end{array}$ \\
\hline $\begin{array}{l}\text { Yami, Rodrigo, } \\
\text { Jorge, Raquel, } \\
\text { Leiza. }\end{array}$ & $\begin{array}{l}\text { Yami (relativa), } \\
\text { Raquel (relativa). }\end{array}$ & $\begin{array}{l}\text { Rodrigo, Jorge, } \\
\text { Camila, Pedro, } \\
\text { Yami e Daniel } \\
\text { (relativa). }\end{array}$ & $\begin{array}{l}\text { Dissonância total: } \\
\text { Lúcia, Rodrigo, Niara, } \\
\text { Tânia, Ana, Jorge, } \\
\text { Tanishia, Cátia, Pedro, } \\
\text { Raquel, Leonor, } \\
\text { Lucinda, Djamila, Alice, } \\
\text { Soraia, Manuela. } \\
\text { Dissonância relativa: } \\
\text { Yami, Luísa, Rosa, } \\
\text { Isabel, Jamilia, } \\
\text { Joaquim, Tiago, Sofia, } \\
\text { Joana, Gustavo, Daniel, } \\
\text { Natasha. } \\
\text { Consonância: Marta, } \\
\text { José, Vanessa. } \\
\text { Consonância Relativa: } \\
\text { Camila, Dafne, Leiza, } \\
\text { Ricardo. }\end{array}$ & $\begin{array}{l}\text { Ana, Camila, Pedro, } \\
\text { Dafne. }\end{array}$ \\
\hline
\end{tabular}

Apesar de, no mundo das culturas juvenis e das fortes influências extraescolares, físicas e virtuais, a socialização da OG não parecer repercutir-se com muita força, são de realçar alguns casos em que tal socialização é claramente consequente sobre o gosto dos participantes, alargando-lhes o leque de repertório musical que ouvem (nomeadamente Djamila, Joaquim, Jamélia e Dafne). Resta saber como tal fraqueza relativa se repercutirá na formação integral destes jovens, no volume global do seu capital e nas estratégias de inserção e de reconhecimento na carreira musical com que muitos deles sonham, mesmo se geralmente os seus planos profissionais mais realistas se orientam para outras profissões (são, no entanto, dez os casos em que o futuro profissional previsível é dentro da música).

Raros são os atores que adquirem a capacidade de mobilizar os recursos para o desenvolvimento de disposições reflexivas sobre a própria arte e técnica musicais 


\begin{abstract}
A relação com a OG é descrita em termos de "paixão", prolongando a intensidade passional que a liga ao instrumento, o violoncelo. Como no amor extremo, reconhece as desvantagens da enorme dedicação: “... passo mais horas com o violoncelo do que a fazer outra coisa... e eu tenho noção que não só passar horas com o violoncelo é essencial, ler é essencial, aprender outras coisas, ver outras coisas... ver o mundo". Marta fala como se o mundo estivesse fora de si, isto é, fora da sua paixão pela música e pelo instrumento, vivido como dedicação quase exclusiva. Antoine Hennion realça, precisamente, a necessidade de atendermos à mediação ativa dos objetos, obras e instrumentos, uma vez que, longe de serem inertes ou passivos, oferecem "uma resistência, uma especificidade ou uma opacidade próprias" (Hennion, 2007: 53), com implicações nas explicações que os atores sociais produzem sobre as suas condutas - não revelam ou exteriorizam apenas; contribuem ativamente para as dinâmicas e convenções dos mundos da música.

O discurso do "amor pela música" permeia as suas referências, com nuances sentimentais face aos instrumentos, que the provocam estados de alma e atmosferas psíquicas, remetendo-nos, assim, para a questão do "poder" e das affordances da música (cf. DeNora, 2000; Juslin e Sloboda, 2010; Clarke e Clarke, 2011).

No caso de Marta, esta ideia de "mundo" algo autorreferencial da OG reforça-se pelo cariz endogâmico das sociabilidades, "um bocado tipo a máfia", num entrelaçar denso de (sobre)aprendizagem, aquisição e ativação de capital social que se transforma num modo de vida, alimentando um vasto stock de disposições (dedicação, sacrifício, autenticidade) e competências (disciplina, autonomia, organização e gestão do tempo) claramente transferidas para a forma como encara outros contextos, nomeadamente a escola (“... não é aquela escola em que ah!, pronto, toda a gente tenta ser diferente... é uma escola em que assim ,eh pá!, ninguém está a ligar assim tanto ao que os outros vestem, ninguém tem essas preocupações"), mas também, e principalmente, a relação com os outros e a construção de uma identidade ("A minha maior preocupação não é se tenho o cabelo arranjado... e se não fosse a Geração não seria assim, não é?).

Em suma, a OG atua como uma segunda família, preenchendo provavelmente alguns vazios de socialização da primeira, em que as preocupações materiais levam os progenitores a sugerirem "uma melhor vida", algo que, profissionalmente, "desse dinheiro".
\end{abstract}

Figura 3 Excerto de retrato: Marta ou a "paixão" pela música

(apenas presentes em Marta, Joana, Jamélia, Vanessa e Tiago), potencialmente atuantes quer como futuros públicos ouvintes, quer como músicos profissionais. Tal reflete o facto de, na generalidade dos casos, a música ser experienciada por estes jovens apenas nos seus aspetos afetivos mais imediatos, concretos e envolventes. Já o desenvolvimento de disposições musicais afetivas (amor/paixão pela música e/ou instrumento) é mais frequente (em 14 casos - cf. quadro 3), tal como acontece no caso de Marta.

\title{
Notas finais e inquietações
}

A presente pesquisa empírica permitiu dar conta de dois tipos de preocupações analíticas e levanta algumas inquietações de (e com?) futuro, sem resvalar, assim o esperamos, para dicotomias infecundas analiticamente e incapazes de traduzirem a complexidade e os sentidos da socialização de orquestra (expressivo $v$ s. instrumental; satisfações intrínsecas vs. satisfações extrínsecas; disposições éticas vs. disposições estéticas; etc.) e evitando, ainda, as perspetivas legitimistas que apenas veem nestas experiências formas impuras e menores de aprendizagem (Mota e Lopes, 2016).

Por um lado, respondendo à vontade dos investigadores de contribuir para um diálogo vivo e fecundo com o núcleo duro da teoria social, elucidou condições 
contextuais e de percurso favoráveis ou inibidoras de disposições e competências sociais, remetendo-as para a sua génese e identificando claramente as condições da sua transferência e metamorfose. De igual modo, revelou o peso dos projetos e futuros possíveis imaginados na negociação e definição das trajetórias. Finalmente, descortinou modos de articulação entre agência, constrangimentos estruturais e reflexividade, mostrando o peso dos percursos na explicação do presente e na antecipação do futuro. Todas estas dimensões de análise aumentam a visibilidade sobre os modos de produção de indivíduos singulares, singularmente socializados em processos e contextos múltiplos, que se articulam em disposições ora combinadas, ora contraditórias.

Por outro lado, em termos de análise de um contexto particular, revelou a força socializadora da OG em dimensões como a criação e/ou mobilização de disposições e competências favoráveis ao sucesso escolar, particularmente quando antecedidas e/ou reforçadas pelos meios familiares, em alguns casos por oposição à escola (a OG oferece atmosferas pedagógicas, conviviais e performativas mais apelativas), noutros em articulação.

AOG parece igualmente eficaz na ativação de novas redes de sociabilidade, mais ricas em extensão e qualidade do capital social, o que desperta por vezes nos atores mecanismos de evitamento ou distanciamento face a pertenças anteriores, particularmente quando associadas a algum tipo de auto ou heterorrelegação/estigmatização socioterritorial. Aliás, a realização de concertos em salas altamente prestigiadas (conservatórios, Casa da Música, Centro Cultural de Belém, Aula Magna), incluindo digressões internacionais, incentiva a aquisição de competências cosmopolitas.

Finalmente, a OG cria e/ou reforça alguns projetos de carreira profissional no mundo da música, não raras vezes associados a intencionalidades mais ou menos explícitas de mobilidade social. Os resultados na modelação de universos de práticas culturais atravessados por referências do repertório clássico e erudito são todavia moderados. Apesar de notáveis exceções, as orientações dos retratados são relativamente homogéneas e niveladas pela exposição a traços "comerciais" das culturas juvenis. No entanto, o facto de estes jovens estudarem, ensaiarem e tocarem um tipo de repertório com o qual a maior parte das vezes não estavam familiarizados e cujas trajetórias passadas não fariam adivinhar - como produtores culturais - é por si só um aspeto importante que não pode ser negligenciado enquanto marca significativa no seu percurso e cujos efeitos globais esta pesquisa não poderia ainda descortinar.

No final, uma questão se impõe com alguma crueza. Atuará a OG como mais uma instituição de educação compensatória, ainda que particularmente eficaz, contribuindo ora para a integração escolar, ora para a integração social mais vasta, ora para ambas, ou será capaz de instituir redireccionamentos sociologicamente improváveis ou até inesperados nas vidas dos seus participantes? Em termos mais concretos, será o stock de disposições gerado pela socialização orquestral necessário e suficiente para a inserção qualificada em termos laborais? E, em caso negativo, resistirão estas disposições (autonomia, responsabilidade, abertura, auto-organização, solidariedade e coordenação) a contextos profissionais desqualificantes e regressivos? Só uma investigação seguindo as trajetórias futuras dos participantes poderá responder a estas inquietações de e sobre percursos. 


\section{Referências bibliográficas}

Archer, Margaret (2003), Structure, Agency and the Internal Conversation, Cambridge, Cambridge University Press.

Baudelot, Christian, e Roger Establet (1992), Allez les Filles! Paris, Seuil.

Bento, Ricardo (2014), "Orquestra da Boba: lugar de sonoridades plurais", Sociologia, Problemas e Práticas, 76, pp. 69-85.

Boia, Pedro dos Santos (2015), “Das tensões entre desmistificar e reconhecer os discursos ao repensar o 'social': manifesto por uma sociologia eclética", Sociologia, 29, pp. 105-128.

Boia, Pedro dos Santos, e João Teixeira Lopes (2012), “Do 'flashar' dos 27 à techno-clubber de 40: retrato sociológico de Maria", em João Teixeira Lopes (2012), Registos do Ator Plural. Bernard Lahire na Sociologia Portuguesa, Porto, Afrontamento, pp. 57- 90.

Bourdieu, Pierre (1972), Esquisse d'Une Théorie de la Pratique. Précédé de Trois Etudes d'Ethnologie Kabyle, Genebra, Droz.

Bourdieu, Pierre (1980), Le Sens Pratique, Paris, Les Editions de Minuit.

Bourdieu, Pierre (1983), Sociologia, org. Renato Ortiz, São Paulo, Ática (col. Grandes Cientistas Sociais).

Bourdieu, Pierre (1993), “Comprendre”, em La Misère du Monde, Paris, Seuil, pp. 903-925.

Bourdieu, Pierre (2010), A Distinção. Uma Crítica Social da Faculdade do Juízo, Lisboa, Edições 70.

Caetano, Ana (2011), "Para uma análise sociológica da reflexividade individual", Sociologia, Problemas e Práticas, 66, pp. 157-174.

Caldas, M. (2007), “Tocar y Luchar". Contributos de Uma Perspectiva Antropológica em Projectos de Arte/Educação. Monografia de Pesquisa Antropológica, Lisboa, Universidade Nova de Lisboa, Faculdade de Ciências Sociais e Humanas, Departamento de Antropologia, licenciatura de Antropologia.

Caldas, M. (2008), "A música como meio de intervenção social: a importação de um modelo de sucesso para o contexto português", Revista de Educação Musical, 131, pp. 43-50.

Clarke, David, e Eric F. Clarke (orgs.) (2011), Music and Consciousness. Philosophical, Psychological, and Cultural Perspectives, Oxford, Oxford University Press.

Corcuff, Philippe (2002), "Pour une nouvelle sociologie critique : éthique, critique herméneutique et utopie critique", em Jean Lojkine, Les Sociologies Critiques $d u$ Capitalisme, Paris, Presses Universitaires de France.

Costa, António Firmino da (2012), Desigualdades Sociais Contemporâneas, Lisboa, Mundos Sociais.

Costa, António Firmino da, João Teixeira Lopes, e Ana Caetano (orgs.) (2014), Percursos de Estudantes no Ensino Superior, Lisboa, Mundos Sociais.

DeNora, Tia (2000), Music in Everyday Life, Cambridge, Cambridge University Press.

DeNora, Tia (2003), After Adorno. Rethinking Music Sociology, Cambridge, Cambridge University Press.

Elias, Norbert (1994), A Sociedade dos Indivíduos, Rio de Janeiro, Jorge Zahar Editor.

EMCN (2009), Projecto Especial Orquestra Geração, Lisboa, Escola de Música do Conservatório Nacional.

Hennion, Antoine (2007), La Passion Musicale, Paris, Métailié. 
Juslin, Patrik, e John Sloboda (orgs.) (2010), Handbook of Music and Emotion, Oxford, Oxford University Press.

Lahire, Bernard (1995), Tableaux de Familles. Heurs et Malheurs Scolaires en Milieux Populaires, Paris, Gallimard/Seuil.

Lahire, Bernard (1998), L'Homme Pluriel. Les Ressorts de l'Action, Paris, Nathan.

Lahire, Bernard (2002), Portraits Sociologiques. Dispositions et Variations Individuelles, Paris, Nathan.

Lahire, Bernard (2012), Monde Pluriel. Penser l'Unité des Sciences Sociales, Paris, Seuil. Lopes, João Teixeira (1997), Tristes Escolas. Práticas Culturais Estudantis no Espaço Escolar Urbano, Porto, Afrontamento.

Lopes, João Teixeira (2014), “Elogio da complexidade: projeto, metamorfose e campo de possibilidades em Gilberto Velho", em Celso Castro e Graça Índias Cordeiro (orgs.), Mundos em Mediação. Ensaios ao Encontro de Gilberto Velho, Rio de Janeiro, FGV Editora.

Melo, Maria Benedita Portugal e (2005), “Os circuitos da reflexividade mediatizada: apresentação de dados preliminares”, Análise Social, XL (3), pp. 595-617.

Mota, Graça, e João Teixeira Lopes (2016), Crescer a Tocar na Orquestra Geração, Vila do Conde, Verso da História.

Pappámikail, Lia (2013), Adolescência e Autonomia. Negociações Familiares e Construção de Si, Lisboa, Imprensa de Ciências Sociais.

Perrenoud, Philippe (1994), Métier d'Elève et Sens du Travail Scolaire, Paris, ESF.

Roldão, Cristina (2014), Fatores e Perfis de Sucesso Escolar "Inesperado", Lisboa, ISCTE-IUL.

Sanchez, F. (2008), "Non-formal music education outside the school of music", em Sílvia Malbrán e Graça Mota (orgs.), Proceedings of the 22nd International Seminar on Research in Music Education, Porto, 13-18 de julho de 2008.

Schutz, Alfred (1951), "Making music together: a study in social relationship", Social Research, 18 (1), pp. 76-97.

Setton, Maria da Graça Jacinto (2010), “Processos socializadores, práticas de cultura e legitimidade cultural", Estudos de Sociologia (São Paulo), 1, p. 1.

Small, Christopher (1998), Musicking, The Meanings of Performing and Listening, Hanôver, NH, Wesleyan University Press.

Tap, Pierre (org.) (1986), Identités Collectives et Changements Sociaux, Toulouse, Privat.

Van Zanten, Agnès (1990), L'Ecole et L'Espace Local. Les Enjeux des Zones D'Education Prioritaire, Lião, Presses Universitaires de Lyon.

Velho, Gilberto (2003), Projeto e Metamorfose. Antropologia das Sociedades Complexas, Rio de Janeiro, Jorge Zahar Editor.

Vieira, Maria Manuel (org.) (2007), Escola, Jovens e Media, Lisboa, Instituto de Ciências Sociais.

Wenger, Etienne (2006), “Communities of practice: a brief introduction”, Communities of Practice, disponível em: http://wenger-trayner.com/introduction-to-communities-of-practice (última consulta em 08/06/2015).

Willis, Paul (1977), Learning to Labour, How Working Class Kids Get Working Class Jobs, Farnborough, Saxon House. 
João Teixeira Lopes. Investigador do Instituto de Sociologia da Universidade do Porto/Departamento de Sociologia da Faculdade de Letras da Universidade do Porto. E-mail: jmteixeiralopes@gmail.com

Pedro dos Santos Boia. Investigador do CIPEM, Centro de Investigação em Psicologia da Música e Educação Musical, polo do IPP do INET-md, Instituto de Etnomusicologia - Centro de Estudos em Música e Dança.

E-mail: psantosboia@gmail.com

Ana Luísa Veloso. Investigadora do CIPEM, Centro de Investigação em Psicologia da Música e Educação Musical, polo do IPP do INET-md, Instituto de Etnomusicologia - Centro de Estudos em Música e Dança.

E-mail: anaveloso@ese.ipp.pt

Matilde Caldas. Investigadora da Universidade Católica de Lisboa e do CIPEM, Centro de Investigação em Psicologia da Música e Educação Musical, polo do IPP do INET-md, Instituto de Etnomusicologia - Centro de Estudos em Música e Dança. E-mail: matildecaldas@gmail.com

Receção: 15 de fevereiro de 2016 Aprovação: 14 de outubro de 2016 